\title{
O SINGULAR E O COLETIVO: POR UMA POLÍTICA DO NÃO-TODO
}

\author{
The Singular and the Collective: For a Policy of the Non-Whole
}

El Singular y el Colectivo: Por una Política del No-Todo

\section{Le Singulier et le Collectif : Pour une Politique du Pas-Tout}

10.5020/23590777.rs.v20iEsp2.e9132

\begin{abstract}
Ana Cristina Costa de Figueiredo 9 iD
Professora titular do Instituto de Psiquiatria - IPUB/UFRJ, Doutora em Saúde Coletiva pelo Instituto de Medicina Social - IMS/UERJ; Participante do GT da ANPEPP "Psicanálise, Política e Clínica".
\end{abstract}

\section{Resumo}

Este texto apresenta uma discussão em torno do tema do singular e do coletivo e traz uma proposta para pensar certo tipo de experiência coletiva fazendo um contraponto com outras formações de grupo ou de massa, como as analisadas por Freud, e também grupos fechados de organização mais totalitária. Sustenta a proposta de formas mais democráticas de organização coletiva que seriam compatíveis com o conceito de "não-todo", tal como definido pela psicanálise, e apresenta dois exemplos de experiências coletivas que ilustram essa proposta.

Palavras-chave: singular; coletivo; democracia; psicanálise.

\section{Abstract}

This text presents a discussion around the theme of the singular and the collective and brings a proposal to think about a specific type of collective experience, making a counterpoint with other group or mass formations, such as those analyzed by Freud, and also closed groups of more organized organization totalitarian. It supports the proposal of more democratic forms of collective organization that would be compatible with the concept of "non-whole", as defined by psychoanalysis, and presents two examples of collective experiences that illustrate this proposal.

Keywords: singular; collective; democracy; psychoanalysis.

\section{Resumen}

Este texto presenta una discusión sobre el tema del singular y del colectivo y trae una propuesta para pensar cierto tipo de experiencia colectiva haciendo un contrapunto con otras formaciones de equipo o de masa, como las analizadas por Freud, y también equipos cerrados de organización totalitaria. Apoya la propuesta de formas más democráticas de organización colectiva que serían compatibles con el concepto de "no-todo", tal como definido por el psicoanálisis, y presenta dos ejemplos de experiencias colectivas que ilustran esta propuesta.

Palabras-clave: singular; colectivo; democracia; psicoanálisis.

\section{Résumé}

Ce texte présente une discussion autour du thème «singulier» et «collectif» et apporte une proposition de réflexion sur un certain type d'expérience collective, en faisant un contrepoint avec d'autres formations de groupe ou de masse, comme celles analysées par Freud, et aussi des groupes fermé à une organisation plus totalitaire. Cet article soutient la proposition de formes plus démocratiques 
d'organisation collective qui seraient compatibles avec le concept de "pas-tout ", tel que défini par la psychanalyse, et présente deux exemples d'expériences collectives qui illustrent cette proposition.

Mots-clés : singulier ; collective ; démocratie ; psychanalyse.

\section{Freud e a Psicologia das Massas}

O fenômeno que vivemos hoje no Brasil, a partir das eleições de 2018, mas que não é exclusivo de nossa experiência política, será que pode ser definido como fenômeno de massa ou de grupo, tal qual Freud (1921/1978a) postulou a partir da teoria de Le Bon (1895./1963)? Podemos responder que, de certo modo, sim, mas, de um modo peculiar, talvez não.

Por um lado, seguimos com Freud (1921/1978a), que aponta a sugestionabilidade, ou contágio, e fatores inconscientes como base da produção desse fenômeno. Além disso, como afirma Le Bon (1895./1963) na leitura de Freud, o indivíduo isolado pode ser culto e civilizado, mas, numa multidão, pode se tornar bárbaro, reduzir sua capacidade intelectual e agir por impulso, chegando à violência, à ferocidade e, até mesmo, ao heroísmo contrário a qualquer esforço de autopreservação. $\mathrm{O}$ grupo (ou massa) é crédulo e aberto à influência, não possui faculdade crítica nem admite o improvável. Pensa por imagens que se combinam por associação sem qualquer relação com a realidade. Seus sentimentos são sempre muito simples e exagerados, e não permitem espaço para dúvida ou incerteza. Tudo se passa nos extremos e, se uma suspeita é expressa, imediatamente se transforma em certeza, ou uma antipatia, e pode resultar em um ódio furioso.

Por outro lado, ainda com Freud (1921/1978a), o fenômeno de grupo também opera pela via do amor. No caso, o amor ao líder ou ao ideal, por onde se dariam as identificações, seja por contágio (identificação histérica) - como no exemplo das meninas do internato que se identificam com a imagem da mulher que perdeu seu amor, sofrendo todas da mesma perda - seja na identificação pela via do objeto idealizado (identificação ao traço) e sua incorporação, ainda que parcial. É nesse ponto que pensamos haver uma diferença importante.

O fenômeno que estamos acompanhando no Brasil e em outras partes do mundo ocidental, impulsionado pelo capitalismo em sua vertente neoliberal e pelas crises que ele gera em seu próprio sistema, ao se aliar a uma estratégia de poder protofascista, não parece passar pela via do amor que resulta nas identificações. Antes, parece haver uma ruptura em relação à identificação com os ideais e uma espécie de "corrida do ouro" em direção aos objetos de consumo, o que, de certa forma, parece se aproximar da relação ao objeto fetiche - estabelecendo-se, portanto, mais na via do gozo do que na via do amor ou do desejo. Na psicanálise, sabemos que o amor já é o resultado de uma perda do gozo, que, por sua vez, originase por meio da ausência do objeto de satisfação. Precisamente, é a renúncia ao gozo imediato o que permite que o amor se manifeste no lugar da perda. Quando predomina a via do gozo, a busca incessante do objeto deve vir a suprir a perda original.

Lacan (1992) aponta o discurso do capitalista, com seu empuxo ao gozo do objeto, como o único que não faz laço com o outro, que não faz laço social, e se perde numa espécie de consumação do objeto no autoerotismo e no individualismo levado à sua potência máxima na experiência do consumo.

Retomando o fenômeno de grupo/massa, destacamos aqui um ponto importante para compreendê-lo: é necessário um estímulo excessivo para ativar seu poder de ação. Seja quem for que queira produzir algum efeito sobre ele, não necessita de nenhuma ordem lógica em seus argumentos. Basta exagerar e repetir o mesmo mote ad nauseam. Qualquer profissional de propaganda sabe disso, desde Goebbels, e explora essa característica sem pudor.

Sem dúvida, esse fenômeno se encontra em muitas manifestações de massa ou grupo e podemos percebê-lo em diversos momentos de nossa história contemporânea. O que parece ser novo é como se dá esse encantamento das massas ou grupos por meio de mídias sociais virtuais, que são, atualmente, as mais poderosas ferramentas da propaganda capitalista, para fins de consumo ou fins políticos. A massa se virtualizou e, assim, se "invisibilizou", ou se deu a ver de outro modo. Consequentemente, as relações sociais e intersubjetivas sofreram grandes abalos.

As disputas ou confrontos vão além do "narcisismo das pequenas diferenças", que pressupõe uma rivalidade entre iguais: mesmo podendo levar à morte ou à aniquilação do outro semelhante, essa rivalidade pode ser barrada, justo pelo que de semelhante pode se localizar em dado momento do confronto. Freud (1921/1978a) traz uma metáfora interessante dessa intolerância ao semelhante na imagem do porco-espinho: quando dois porcos-espinhos sofrem as intempéries do inverno, ou bem ajustam seus espinhos de modo a não se ferir para melhor se aquecerem, ou morrerão de frio.

Quando essa rivalidade não mais se refere ao semelhante, temos um risco maior de não mais nos reconhecermos como pertencentes ao mesmo modo de existência. Aqui, alertamos para o fato de que, no laço social, algo acontece hoje que não se reduz apenas aos fenômenos de massa/grupo, tais como foram descritos por Le Bon (1895./1963) e analisados por Freud. 
Especulando, podemos dizer que aqui temos mais uma concentração de gozo que vai além, ou fica aquém, da via do amor e do ódio como seu avesso: amoródio, neologismo criado por Lacan (1985), que seria próprio do narcisismo no registro imaginário. Quinet (2018) ousa acrescentar que a via do amor fica de fora e o que aparece é o ódio aliado à ignorância uma das paixões do ser em Lacan (1983). Ele propõe, ainda, um novo arranjo, que condensa os termos no "ignoródio" (termo usado por Quinet). Essa paixão, por assim dizer, teria a peculiaridade de não fazer laço, uma vez que estaria sob a égide da pulsão de morte. Possuiria apenas alguma coloração erótica necessária para poder matar, eliminar, exterminar o que seria eleito e definido como o "inimigo", e não mais o rival: seja o comunista, seja o de orientação sexual diversa do heteronormativo, seja negro (judeu?), seja imigrante, seja pobre, seja de classe social inferior etc.

Encontramos, nas propostas protofascistas contemporâneas, a reedição, em certa medida, do que já conhecemos na história do século XX, mas que avança com novas táticas e ferramentas, inexistentes anteriormente, produzindo efeitos mais capilarizados e permanentes na via do "ignoródio". Afinal, que coletivo seria esse que se produz, valendo-se, por um lado, dos recursos da sugestão ou contágio, mas produzindo efeitos tão devastadores que podem esfacelar e dissolver esse mesmo coletivo de massa ou grupo, resultando no pior do individualismo, que difere radicalmente da singularidade? Aqui temos um ponto importante. Na singularidade, temos o que é mais íntimo e único em cada um, supondo-se, nessa unicidade, não uma unidade, e sim uma particularidade que, ao estabelecer a diferença, instaura a possibilidade de se existir a partir dela.

Já o individualismo pressupõe certo fechamento diante do próprio semelhante. Meu "igual" pode ser meu "rival" é uma máxima que se impõe. Em outras palavras, no individualismo, o semelhante como rival convoca à competição, e o diferente toma o lugar do inimigo. Já a singularidade pressupõe a diferença como marca indelével de cada um, portanto, a diferença se instaura como premissa básica, e não a semelhança. Aonde isso pode nos levar? Retomaremos esse ponto adiante.

A exacerbação do individualismo, como consequência e manutenção do modus operandi social do capitalismo avançado e seus gadgets, acaba por desconhecer a singularidade e mesmo estranhar suas manifestações, num movimento isolacionista em nome de uma igualdade artificial, meramente imaginária, ameaçada por qualquer sinal de diferença. Como sair desse impasse e restaurar a possibilidade de coletivos que não sejam subprodutos de estados pseudo-hipnóticos característicos das massas (ou grupos fechados)?

\section{Totalitarismo e Democracia: De que Coletivos se Trata?}

Já temos uma longa discussão em andamento no campo da geopolítica sobre o avanço da ultradireita na Europa e nos EUA. A ameaça de uma retomada do nazifascismo e sua estratégia de manipulação das massas aponta para uma crise da democracia, que caminha a par e passo com os avanços do chamado "ultra-capitalismo" contemporâneo. Numa tentativa de explicar o fenômeno atual que não se reduz ao caso brasileiro, por exemplo, temos autores como Steven Levitsky e Daniel Ziblatt (2018) em seu famoso livro Como as democracias morrem (How democracies die). Sua análise tem como cerne duas premissas decisivas para esse fracasso: a recusa do contraditório, ou seja, recusa de reconhecer o outro como seu semelhante (humano) na diferença (subjetiva), e a consequente eleição de um inimigo a combater. Mais uma vez, evoca-se o método eficaz da propaganda de Goebbels como evidência dessa estratégia.

Levitsky e Ziblatt (2018) propõem uma espécie de litmus test, um crivo de avaliação que possa atestar sem ambiguidade o que seria característico de um regime ou líder autoritário que ameaçaria os princípios democráticos, seja na política, seja na organização social. Em outras palavras, o que seria característico de um comportamento "fascista". Entendemos aqui que esse teste pode se aplicar a um governante, líder político ou a um determinado grupo. São quatro categorias que se articulam. Apresentamos aqui brevemente: 1. Rejeição ou comprometimento fraco com as regras do jogo democrático; 2 . Negação da legitimidade dos oponentes políticos; 3. Tolerância ou encorajamento à violência; 4. Prontidão para reduzir as liberdades civis dos oponentes, incluindo a mídia.

Levitsky e Ziblatt (2018) diferenciam regras constitucionais das normas. Essas seriam uma espécie de conjunto de costumes presentes no mundo político e social, e seriam essenciais na manutenção da democracia, uma vez que definem quais são os comportamentos não aceitáveis, mesmo que legais, dos agentes políticos. Isto é, as normas estariam mais ligadas ao ethos do que às leis. O que pode ser legal pode não ser ético ou mesmo justo.

Além disso, alertam para o potencial destrutivo da polarização em uma competição eleitoral, por exemplo, mas que podemos estender para as relações sociais em geral. A tolerância mútua entre adversários políticos refere-se à ideia de que os rivais jogam de acordo com as regras constitucionais e de que aceitamos seu direito a existir. Quando partidos opostos se tratam como inimigos, a tendência a se utilizar de meios antiéticos e abusivos cresce. Se deslocarmos essa análise para modos de organização de grupos ou massas, teremos uma ideia das consequências nefastas dessa polarização.

Entre leis, regras e normas há distinções importantes que podem nos ajudar a compreender melhor não só como as democracias podem fracassar, mas também como os laços sociais podem se fragilizar ou mesmo se romper, ou se petrificar em arranjos fechados em que não há mais lugar para a diferença. Esses coletivos, que podemos tipificar como totalitários, 
podem ser mais complexos do que os estudados por Le Bon (1895./1963) e analisados por Freud. Podem ser extremamente nocivos em seu funcionamento e propósito, e regidos quase exclusivamente pela pulsão de morte. O laço amoroso não predomina, e sim o gozo mortífero, visando à eliminação do inimigo. Temos no grupo americano Ku Klux Klan a sua forma mais radical de expressão, mas também na juventude nazista da Alemanha dos anos 30 ou nos Carecas, grupo neonazista da periferia de São Paulo, entre outros.

\section{O que propor para o Coletivo?}

Em princípio, é mister sobreviver a essa devastação. Cada um de nós ou cada grupo social deve construir suas estratégias visando um deslocamento fundamental das massas desorganizadas ou violentas para os grupos organizados e produtivos ao modo de uma comunidade.

Mas o que podemos propor, a partir da psicanálise, para a vida coletiva e que lugar possível para o que tanto cultivamos como a singularidade? O que do singular pode se produzir a partir do coletivo?

Não há singular fora do laço social. Qualquer invenção do sujeito deve encontrar lugar num laço específico que seja no social, deve buscar um modo de reconhecimento de si no outro pela via imaginária do semelhante, mas também pelo reconhecimento da diferença, pela via simbólica como marco da castração, que sempre pressupõe uma perda estrutural, perda de gozo, perda do objeto primordial.

Como distinguir o laço social, como modo singular de enlaçamento no coletivo, do turbilhão homogêneo da massa ou grupo que abole ou descaracteriza a dimensão singular do ser falante?

Se partirmos da premissa de que a singularidade se instaura a partir da diferença, teremos a possibilidade de produzir coletivos de outro modo, não mais a partir de pretensas homogeneizações em torno do líder. Essa proposta pode soar como uma utopia, mas talvez seja mesmo disso que precisamos. Um novo "topos" a ser atingido a cada passo. Não mais pela unidade, o que não exclui a união ou a parceria, e sim pela combinação de elementos heterogêneos que desenvolvam uma tolerância com base em princípios comuns.

Teríamos algumas indicações a serem exploradas e desenvolvidas por todos nós que buscamos saídas dignas a essa onda destrutiva do ultra-capitalismo contemporâneo, pois, cada vez mais, aprofunda as desigualdades sociais e econômicas que têm como consequência a produção de subjetividades avessas ao diferente, tido como um "não igual" a ser banido. Mantémse, desse modo, atrelado ao autoritarismo segregacionista como único modo de controle das populações e dos corpos.

Propomos aqui seguir as indicações de Pierre Dardot e Christian Laval (2017) em seu trabalho sobre o "comum". Em que consiste o comum? Trata-se, sobretudo, de um princípio político que visa a estabelecer uma organização democrática de uso coletivo dos recursos produzidos por uma comunidade grande ou pequena. Associa a busca de uma democracia genuína à implementação de um direito coletivo de uso. Assim, deve-se abrir espaço para criar a necessidade de uma nova ideia de revolução, que articule práticas institucionais básicas que promovam a transformação, em um sentido democrático, das grandes estruturas políticas e econômicas da sociedade. Uma nova utopia? Talvez não.

Dardot e Laval (2017) partem de propostas concretas que possam ter um maior poder de implantação justo por estarem ligadas a diferentes tipos de práticas. Para eles, o comum não é uma coisa, não é um bem. É tudo o que, em um dado momento, uma coletividade decide compartilhar. Além disso, não é o naturalmente comum. Antes, é o que fazemos com que seja comum por um ato político, por um ato instituinte.

De acordo com Dardot e Laval na entrevista concedida a Andrade e Ota (2015), p.313):

Os princípios não têm força senão por seus vínculos com as práticas, as condutas, as lutas. Em campos muito variados (agricultura, informática, artes, ciências, artesanato e indústria, serviços), formas cooperativas e colaborativas de produção, de consumo, de educação e de habitat se desenvolvem em todos os lugares. (...) Experimentações locais e mobilizações de grande escala remetem, portanto, a uma lógica geral que chamamos de comum.

Mais adiante, esclarecendo o uso e a aplicação do termo "comum”, enfatizam:

O termo "comum", de modo muito geral, evoca etimologicamente aquela obrigação com os cidadãos que implica um investimento público. Para os habitantes de uma cidade, "viver juntos" não é, como dizia Aristóteles, pastar uns ao lado dos outros como vacas em um prado, mas participar de uma atividade comum: é uma coatividade que obriga cada um em relação aos outros participantes. Em suma, o "comum” como nós o entendemos deve ser pensado e instituído de acordo com a lógica de autogoverno estendido a todas as formas de atividade coletiva. O autogoverno é a forma política universal do comum. E para ser ainda mais preciso, o princípio do comum comanda a instituição de comuns em todas as áreas, ou seja, a criação 
de instituições sociais, econômicas e culturais, organizadas segundo o princípio do autogoverno. Trata-se de um princípio revolucionário que designa uma tarefa histórica de reinstituição democrática da sociedade. (Andrade \& Ota, 2015, p.314)

A partir dessa proposta, apresentamos dois exemplos pontuais de organizações sociais que bem poderiam exemplificar esse princípio político do "comum", tal como tem sido pensado pelos autores acima. Ambos resultam de ações independentes do Estado ou de seus recursos e se estabelecem na perspectiva do "autogoverno", na contramão do capitalismo avançado que traz o individualismo, a competição e a segregação como fundamentos das relações sociais ou intersubjetivas. Ambos, em seu modo de constituição, driblam a mais-valia que garante o lucro sobre a exploração do trabalho e subvertem a lógica do capital.

\section{A Experiência do MST - Movimento dos Trabalhadores Rurais Sem Terra}

Trata-se de um movimento fundado em 1984 por João Pedro Stédile, altamente organizado, com estrutura administrativa hierarquizada e descentralizada, disseminado em várias partes do país e que ocupa basicamente regiões rurais. É uma organização comunitária de coletivos mais ou menos estáveis - há assentamentos de cerca de 30 anos e outros mais recentes - que comportam, em sua maioria, uma população de camponeses, plantadores e produtores rurais. Estão instalados em cerca de 700 municípios no Brasil e têm cerca de 160 mil crianças estudando no ensino fundamental, em 1800 escolas comunitárias nos acampamentos e assentamentos - faz parte da formação não só a escolaridade formal, mas também uma educação social na perspectiva do compartilhamento de bens materiais e simbólicos. São 30 mil jovens e adultos, sendo em torno de 750 militantes que estudam em cursos universitários em áreas de interesse das comunidades (58 cursaram medicina); dão suporte a mais de 300 mil famílias que estariam na mendicância e na indigência, vivendo nas grandes cidades como rebotalho da sociedade capitalista afluente que produz cada vez mais desigualdade social e econômica (Movimento dos Trabalhadores Rurais Sem Terra [MST], 2018).

Ocupam somente terras improdutivas que devem ser desapropriadas, apoiados na Lei $\mathrm{n}^{\circ} 4.504$ de 1964, que garante a desapropriação de terras que não cumprem sua função social. Hoje o MST é o maior produtor cooperativado de arroz orgânico da América Latina e de produtos orgânicos do Brasil. Somente na safra de 2017 foram produzidos 27 mil toneladas de arroz orgânico. Além disso, o movimento exporta $30 \%$ de sua produção para países como Estados Unidos, Alemanha, Espanha, Nova Zelândia, Noruega, Chile e México (Articulação Nacional de Agroecologia [ANA], 2019). Pagam impostos e tornam produtivas as terras antes improdutivas, e já recuperaram parte da Mata Atlântica. Portanto, é um movimento organizado pelos coletivos, que já tem um destaque dentro da economia brasileira, sem se sustentar na lógica da mais-valia, que caracteriza a exploração do trabalho pelo capital.

Certamente, há ainda o que está por ser feito em relação aos laços entre esses sujeitos no cotidiano de suas vidas e no enfrentamento de toda sorte de dificuldades não apenas materiais. Mas o que importa destacar aqui é que, na orientação do governo eleito em 2018, essa população corre sério risco de ser criminalizada como invasora e expropriadora da propriedade privada, principalmente dos grandes latifúndios. Sua resistência e sobrevivência dependem não só de sua produtividade, mas também de sua mobilização política e do reconhecimento cada vez maior de sua capacidade transformadora dos laços sociais e produtivos, na perspectiva dos coletivos em permanente colaboração, instaurando o "comum" versus modos de laço mais exclusivos, com alto poder de segregação social e exploração da força de trabalho.

\section{A experiência do CPCD - Centro Popular de Cultura e Desenvolvimento}

Trata-se de uma ONG sem fins lucrativos e de utilidade pública federal, estadual e municipal, vinculada ao Terceiro Setor, de natureza privada e função social pública, fundada em 1984, pelo educador e antropólogo Tião Rocha, em Belo Horizonte/MG. Visa a atuar na estratégia da educação popular de qualidade e desenvolvimento comunitário sustentável, tendo a cultura material ou simbólica como matéria-prima e instrumento de trabalho pedagógico. Segue a metodologia geral de Paulo Freire em sua perspectiva dialética de extrair de determinada comunidade o seu saber-fazer para qualificálo e avançar em novos modos de laço social e afetivo, também na contramão do capitalismo e seu modo de produção. A propriedade da produção é compartilhada em forma de mutirões de trabalho coletivo.

$\mathrm{O}$ Centro $\mathrm{CPCD}$ visa à realização de projetos e programas integrados, inovadores, de transformação social e desenvolvimento sustentável, destinados, preferencialmente, às comunidades e cidades brasileiras com menos de 50 mil habitantes, onde vive mais de $95 \%$ da população brasileira. Sua principal proposta é trabalhar na criação de pequenas comunidades ou coletivos autossustentáveis, regidos por princípios éticos de justiça e equidade social, valorizando e qualificando a diversidade cultural brasileira. Em suma, visa a produzir o "comum" como estratégia político-social.

Seus participantes, entre técnicos educacionais e leigos, se colocam na posição de aprendizes permanentes em seu modo de abordagem colaborativa para construir essas comunidades, sempre visando à cidadania a partir do que se apresenta em 
cada grupo social como base para disparar as ações coletivas.

O compromisso desses educadores passa diretamente pelo que Lacan (1988) chamou de "desejo decidido", sem o qual nenhuma de suas ações seria possível, pois grandes são os desafios enfrentados, ora pela própria inércia de grupo dominante nas comunidades, ora pelas dificuldades materiais encontradas na miséria e desamparo dessa população.

Os exemplos são inúmeros dessas experiências inusitadas e bem-sucedidas em comunidades absolutamente desprovidas de qualquer apoio externo ou governamental.

Um dos fundamentos básicos da proposta é localizar, em determinado grupo social ou comunidade, os chamados "pontos de luz", ou seja, voluntários locais que se apresentam como potenciais para a invenção de novas formas de vida. O CPCD trabalha com o que chama de IPDH - Índice Potencial de Desenvolvimento Humano -, por contraste ao IDH, que não inclui justo a "potência", o que se pode produzir, incluindo apenas o que se mede de modo descritivo.

Alguns exemplos: projetos sanitários, como banheiro seco, caixa d'água, compostagem e plantio doméstico (horta em mandala) e permacultura em geral, são alguns recursos utilizados de acordo com as demandas locais, e as ações são sempre colaborativas e partilhadas. Assim, produzem mais qualidade de vida, evitam a contaminação da água e dos rios, e as doenças decorrentes, muitas vezes mortais.

Numa pequena comunidade, uma senhora dizia só saber fazer biscoito de polvilho e, após alguma conversa, revelou como era nomeado: "biscoito escrivido". Nesse ponto, abre-se a possibilidade de invenção, e o biscoito se torna a matéria-prima para iniciar um trabalho de alfabetização de crianças, que passam a aprender a escrever fazendo o biscoito para depois comê-lo. Assim se produziu uma escrita do nome próprio de cada criança. Nome e sobrenome desfilavam na confecção do biscoito a ser saboreado ao fim, inscrevendo a nomeação no simbólico e produzindo interessantes efeitos imaginários na cultura culinária local.

A campanha de combate à mortalidade neonatal que se desenvolve no interior do Maranhão, estado com o menor Índice de Desenvolvimento Humano (IDH) do país, é outro exemplo. O projeto conta com os chamados "pontos de luz", voluntários que recebem as gestantes para pernoite (casa do meio do caminho), além de estabelecerem uma parceria com os agentes comunitários de saúde no acompanhamento do aleitamento materno nos primeiros meses do recém-nascido (mães cuidadoras), com suporte alimentar (plantio doméstico com horta em mandala) e social para as mulheres e famílias.

A marca do CPCD é sempre desenvolver um trabalho de modo lúdico e espontâneo, dando margem à invenção e à surpresa, compartilhando experiências em um cenário muitas vezes hostil ao humano, dada a miséria que comparece implacável no cotidiano dessas pessoas.

Enfim, uma variedade de técnicas que devem ser transmitidas e aprendidas coletivamente, mas sem regras pré-fixadas ou imposições disciplinares na construção dessas pequenas cidades ou vilas; visando, pode-se dizer, ao "comum", tanto em sua dimensão comunitária como em sua perspectiva política na via do autogoverno nos coletivos organizados de modo horizontal.

\section{Para Concluir}

Para concluir, não podemos deixar de tratar de um ponto que é caro à psicanálise e remete ao título deste texto: por que o paradigma do "não-todo"? A que e a quem ele serve?

Seja qual for o modo de organização desses coletivos (mais ou menos produtivos, mais ou menos horizontais ou igualitários em sua estrutura administrativa, mais ou menos capilarizados), é preciso escapar do "efeito de grupo" ou "cola imaginária" de que fala Lacan (1980) ao referir-se ao modelo do cartel para a formação teórica do psicanalista. Portanto, é preciso escapar do fechamento em si mesmo na via do "narcisismo das pequenas diferenças", de que fala Freud (1930/1978b), e do fechamento em grupos como "cola", que produz efeitos de segregação e de exclusão da diferença. Diferença que, como vimos acima, é intrínseca à singularidade que constitui o sujeito.

Sabemos, entretanto, que esse fechamento é um fator inevitável, presente em qualquer agrupamento humano e, por isso mesmo, deve ser reduzido a sua mínima expressão. Como psicanalistas, advertidos sobre as armadilhas cotidianas presentes no laço social pela via narcísica, trabalhamos na direção contrária à segregação e à exclusão da diferença e, consequentemente, contra organizações coletivas totalitárias sustentadas na imagem incontestável do líder ou no dogma como ideal. Sendo assim, podemos dizer que a psicanálise é radicalmente aliada da democracia, uma vez que não sustenta qualquer tipo de arranjo social na via da segregação e exclusão da diferença. A diferença que nos interessa, mais do que o que entendemos por "diferente de", no sentido da comparação entre pessoas ou grupos, é a diferença absoluta, ou seja, a que não é comparável nem mensurável em qualquer tipo de descrição. Essa é a diferença que marca o singular, e só assim se pode pensar em coletivos.

Na psicologia, particularmente nas teorias da percepção, mas que se estende aos modos de subjetivação, encontramos diferentes definições do "todo" que podem mesmo ser incompatíveis. Na perspectiva elementarista, temos o "todo" capturado como a soma das partes. Já na definição da Gestalt, o todo seria a boa forma sintetizada no círculo irredutível a suas partes. 
Podemos dizer que Freud se valeu de ambas as definições. O que o inconsciente registra se instala de modo fragmentário, podendo se combinar por partes na condensação ou deslocamento, mas sem nunca formar um todo. Já o "eu" se organiza numa aparente unidade, ao modo da "boa forma", amalgamando as partes, que são os precipitados das identificações numa ilusão narcísica e, portanto, imaginária, de se constituir como um "todo".

A noção de "não-todo", introduzida por Lacan (1985), inicialmente se refere ao feminino como um modo particular de gozo "não-todo", inscrito no registro fálico da castração que ordena e regula o gozo. Isto é, há algo que escapa a essa organização fálica e se apresenta como um transbordamento, um gozo a mais. Mas também o "não-todo" pode ser entendido como o que não fecha, não tem unidade nem uniformidade; não se apresenta da mesma maneira regulada, permitindo a variação, o imprevisível e a surpresa. $\mathrm{O}$ que nos interessa aqui é justamente introduzir essa dimensão que excede a organização (do grupo), seja em sua unidade ilusória (narcísica), seja em sua normatividade regulada (ordem fálica).

Retomando os dois exemplos apresentados acima, podemos dizer que o primeiro (MST) constitui um coletivo mais organizado na via marcada pela inscrição fálica, mas que, por estar à mercê de políticas repressivas em nome da propriedade privada e do capital, se encontra na franja do instituído e não se inscreve inteiramente nessa ordem. Algo escapa e se manifesta num agrupamento "não-todo" circunscrito pelo controle do Estado que pode ser visto como transgressor. Já o segundo (CPCD) se apresenta na via do improviso, da invenção, de um saber-fazer a cada experiência, em cada comunidade que constitui pequenos agrupamentos que se encontram na contingência "não-toda" instituída na ordem vigente.

Para concluir, podemos pensar em vários outros exemplos. Mas, seja como for, torna-se cada vez mais necessário traçarmos um rumo que deve seguir nessa direção do "não-todo" fechado, do "não-todo" fálico, do "não-todo" que deve fundamentalmente impedir o empuxo a fazer "um", visando ao "todo" em qualquer formação social.

Talvez essa seja a melhor contribuição que temos a dar a partir da psicanálise e com Lacan (1985), visando trabalhar como facilitadores de laços coletivos e comunitários para que o que há de singular possa emergir nessas novas modalidades de arranjos sociopolíticos e econômicos. Mas também podem ser novos arranjos de gozo, fora do predomínio da pulsão de morte, que pretendem burlar e mesmo escapar à fúria predatória do capitalismo avançado de nosso tempo. Capitalismo esse que, com sua mais-valia, explora o trabalho, e com seu correlato, o mais-de-gozar - objeto que presentifica e condensa gozo -, incide sobre os corpos com seu efeito perverso, que segrega e exclui o "comum", numa "política" de controle dos modos de gozo que pode levar ao pior, isto é, ao gozo mortífero de aniquilação da diferença e da singularidade, tornando impossível qualquer arranjo coletivo na via da democracia.

\section{Referências}

Articulação Nacional de Agroecologia [ANA]. (2019). 35 coisas que você precisa saber sobre o MST. Link

Andrade, D. P., \& Ota, N. (2015) Uma alternativa ao neoliberalismo: Entrevista com Pierre Dardot e Christian Laval, Tempo Social, revista de sociologia da USP, 27, 275-315.

Centro Popular de Cultura e Desenvolvimento [CPCD]. (2019). Link

Dardot, P., \& Laval, C. (2017). Comum: Ensaio sobre a revolução no século XXI. São Paulo: Editora Boitempo.

Freud, S. (1978a). Group psychology and the analysis of the ego. In J. Strachey (Ed.), The Standard Edition of the complete psychological works of Sigmund Freud (Vol. 18, pp 67-140). London: Hogarth Press. (Originalmente publicado em 1921)

Freud, S. (1978b). Civilization and its discontents. In J. Strachey (Ed.), The Standard Edition of the complete psychological works of Sigmund Freud (Vol. 21, pp 64-145). London: Hogarth Press (Originalmente publicado em 1930)

Lacan, J. (1980). D’Écolage. Escola Letra Freudiana, 1(0), 50-52

Lacan, J. (1983). O Seminário, livro 1: Os escritos técnicos de Freud (1953-54). Rio de Janeiro: Jorge Zahar.

Lacan, J. (1985). O Seminário, Livro 20: Mais, ainda (1972-73), Rio de Janeiro: Jorge Zahar.

Lacan, J. (1988). O Seminário, Livro 7: A Ética da Psicanálise (1959-1960). Rio de Janeiro, Jorge Zahar.

Lacan, J. (1992). O Seminário, Livro 17: O avesso da Psicanálise (1969-1970). Rio de Janeiro: Jorge Zahar. 
Le Bon, G. (1963). La Psychologie de Foules. Paris: PUF. (Originalmente publicado em 1895).

Lei $n^{\circ} 4.504$, de 30 de novembro de 1964. Dispõe sobre o estatuto da terra, e dá outras providências. Link

Levitsky, S., \& Ziblatt, D. (2018). Como as democracias morrem. Rio de Janeiro: Jorge Zahar.

Movimento dos Trabalhadores Rurais Sem Terra [MST]. (2018). Quem somos. Link

Quinet, A. (2018). A psicanálise e os paradoxos da política da diferença. In: Universidade Estadual do Rio de Janeiro (Org.), Anais do XIII Simpósio do Programa de Pós-graduação em Psicanálise. Rio de Janeiro: UERJ.

\section{Como citar:}

Figueiredo, A. C. (2020). O Singular e o Coletivo: Por uma Política do Não-Todo. Revista Subjetividades, 20(Esp 2. O Contemporâneo à Luz da Psicanálise), e9132. http://doi.org/10.5020/23590777.rs.v20iEsp2.e9132

\section{Endereço para correspondência}

Ana Cristina Figueiredo

E-mail: gois_erika@hotmail.com 